\title{
EMPREGO DE CATALISADORES À BASE DE NÍQUEL PARA HOMO- E COPOLIMERIZAÇÃo DE ESTIRENO
}

Luis Carlos Ferreira Jr., Marcos A. S. Costa*, Luiz Claudio de Santa Maria, Fernanda M. B. Coutinho e Pedro I. C. Guimarães

Instituto de Química, Universidade do Estado do Rio de Janeiro, Rua São Francisco Xavier, 524,

Pavilhão Haroldo Lisboa da Cunha, 20559-900 Rio de Janeiro - RJ

Recebido em 25/4/03; aceito em 1/3/04; publicado na web em 6/7/04

THE USE OF NICKEL-BASED CATALYSTS FOR HOMO-AND COPOLYMERIZATION OF STYRENE. This review deals with the homo- and copolymerization of styrene with nickel catalysts. The catalytic activity, polymer stereoregularity, polymer molecular weight and polydispersity are dependent upon nickel ligands and reaction parameters. Catalysts supported on silica, treated with methylaluminoxane (MAO), have shown higher stereospecificity and activity compared to homogeneous ones. The influence of these parameters is discussed focusing on the elucidation of some aspects of the polymerization mechanism.

Keywords: nickel catalysts; polystyrene; styrene copolymers.

\section{INTRODUÇÃ̃O}

A descoberta da polimerização por coordenação com catalisadores Ziegler-Natta convencionais ativados por compostos trialquilalumínio, e com metalocenos ativados por metilaluminoxano, provocou um grande avanço na produção de novos materiais poliméricos. Esses sistemas catalíticos são capazes de produzir os vários tipos de polietileno comerciais, ou seja, polietileno de alta densidade (HDPE), de baixa densidade (LDPE) e linear de baixa densidade (LLDPE), polipropileno e poliestireno com diferentes taticidades (isotáticos ou sindiotáticos), ou mesmo polipropileno com isoblocos e estereoblocos em sua microestrura ${ }^{1-15}$.

Os catalisadores à base de níquel, por sua vez, despertaram grande interesse nos últimos cinco anos com a descoberta, por Maurice Brookhart e outros pesquisadores, de complexos com ligantes diimínicos. Esses complexos na presença de metilaluminoxano, ou mesmo trialquilalumínio, são capazes de produzir polietileno ramificado, devido à presença de espécies catalíticas que polimerizam por um mecanismo de isomerização conhecido como "chain-running" (Figura 1) que compete com a inserção de etileno. Outra característica desses catalisadores é a ocorrência de um mecanismo de re-inserção 1, $\omega$ (Figura 2), que explica a formação de poliolefinas com teor de ramificações mais baixo que o esperado, quando propileno, hexeno e outras olefinas de cadeia longa são polimerizadas ${ }^{16-18}$.

Por outro lado, a homopolimerização de estireno sobre catalisadores de níquel, principalmente aqueles com acetilacetonas como ligantes, tem demonstrado uma grande versatilidade na obtenção de poliestireno e seus copolímeros ${ }^{19-33}$. A presença de triisobutilalumínio ou de trimetilalumínio residual no metilaluminoxano exerce uma grande influência sobre a atividade catalítica e a estereoespecificidade dos catalisadores de níquel na polimerização de estireno $^{23,26}$. Outro fator de grande influência é a presença de bases de Lewis tais como aminas e fosfinas, que podem tanto aumentar o peso molecular como a isotaticidade do poliestireno ${ }^{20-23}$.

$\mathrm{O}$ acetilacetonato de níquel pode ser suportado em sílica ou alumina, levando à formação de um sistema catalítico com atividade e estereoespecificidade superiores ao sistema homogêneo ${ }^{24-26}$. Outra

*e-mail: masc@uerj.br

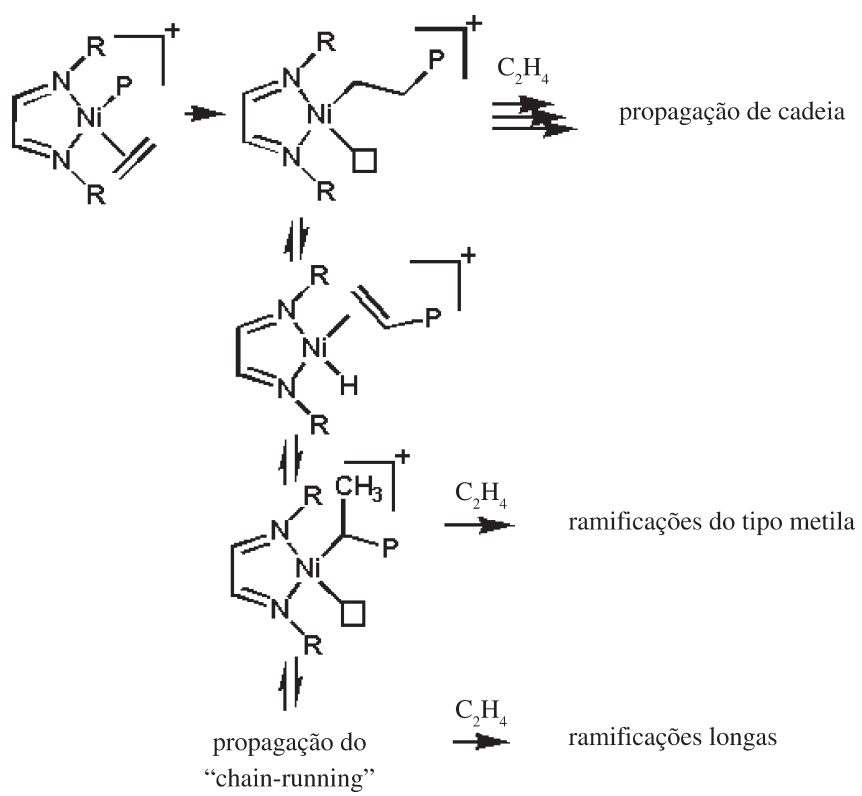

Figura 1. Mecanismo de formação de ramificações ${ }^{18}$

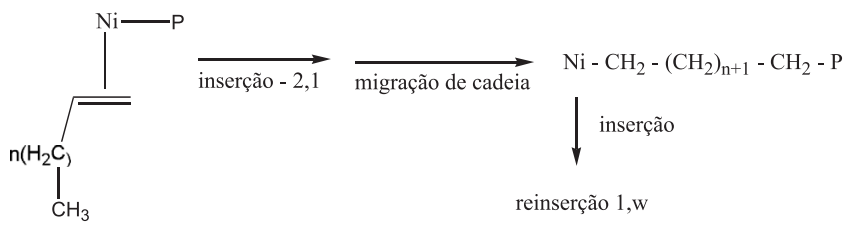

Figura 2. Mecanismo de reinserção $1, \omega^{16}$

característica desse catalisador é sua capacidade de copolimerizar estireno com metacrilato de metila ${ }^{33}$, devido à sua menor sensibilidade à presença de grupamentos polares. Neste aspecto, difere de outros catalisadores, que somente são capazes de copolimerizar monômeros polares em condições reacionais especiais, tais como (a) com proteção do grupamento polar, através da complexação com 
alquilalumínio $^{34,35}$; (b) com a utilização de comonômeros de cadeia longa com o grupamento polar na extremidade, que impede a sua desativação, devido ao maior afastamento desse grupamento ${ }^{35}$ e (c) com a utilização de comonômeros com um grupamento não polar e reativo para uma modificação posterior do copolímero ${ }^{36}$.

A literatura apresenta várias revisões sobre catalisadores ZieglerNatta, metalocênicos e com ligantes diimínicos ${ }^{1-18}$. No entanto, não são encontradas revisões sobre catalisadores à base de níquel para homo- e copolimerização de estireno. Sendo assim, o objetivo deste trabalho é apresentar os principais catalisadores de níquel encontrados na literatura para a polimerização de estireno, dando ênfase aos sistemas catalíticos, ao mecanismo de polimerização e à homo- e copolimerização de estireno.

\section{SISTEMAS CATALÍTICOS À BASE DE NÍQUEL}

A estereoespecificidade do catalisador, o peso molecular e a polidispersão do polímero produzido são características que podem ser controladas por meio da escolha adequada do sistema catalítico. A utilização de diferentes ligantes, suportes, cocatalisadores ou bases de Lewis pode modificar o comportamento do catalisador levando à produção de polímeros com diferentes propriedades e aplicações.

\section{Efeito dos ligantes}

Os ligantes dos catalisadores de níquel apresentam uma grande influência sobre a atividade catalítica na polimerização de estireno. Além disso, influenciam também o peso molecular e a polidispersão do polímero. Uma grande variedade de ligantes de catalisadores de níquel é apresentada na Tabela $1^{19}$. Os catalisadores mais ativos são o dicloreto de níquel e o acetilacetonato de níquel. O dicloreto de níquel, na presença de metilaluminoxano, leva à formação de uma mistura heterogênea. Por outro lado, o acetilacetonato de níquel, também na presença de metilaluminoxano, leva à formação de uma mistura homogênea e de cor marrom. No final da reação, partículas pretas são removidas juntamente com o polímero. Provavelmente, essas partículas são formadas pela redução do níquel para o estado de oxidação zero.

Os complexos 9 e 10 da Tabela 1 são menos ativos que os demais, provavelmente devido à dificuldade de redução da espécie $\mathrm{Ni}^{2+}$ para $\mathrm{Ni}^{1+}$ que é a espécie ativa na polimerização.

A presença de ligantes organofosforados acarreta uma diminuição da atividade catalítica, sendo que o complexo com fosfito de trietila apresenta maior atividade que os complexos com ligantes fosfínicos. Observa-se também que o aumento no volume do ligante fosfínico leva à diminuição da atividade catalítica, à exceção do catalisador com triciclo-hexilfosfina como ligante. O caráter ácido do ligante, por sua vez, tem pouca influência sobre a atividade catalítica como pode ser observado na Tabela 1 (catalisadores 7 e 8).

Os polímeros possuem pesos moleculares que variam na faixa de 9000 a 24000 g/mol. O maior peso molecular (95000 g/mol) obtido com o catalisador 15 pode ser conseqüência do efeito de estereoimpedimento causado pelo ligante, que diminuiria as reações de terminação de cadeia.

$\mathrm{O}$ aumento da acidez dos ligantes em catalisadores de níquel como no bis-( $\alpha$-nitroacetofenona) de níquel, o bis-(hexa-fluoroacetilacetonato) de níquel e o bis-(acetilacetonato) de níquel, cujos pKa's são respectivamente 5,59, 4,2, 8,8, não influencia a atividade catalítica mas, de maneira geral, pode levar ao aumento no peso molecular do poliestireno (Tabela 2) ${ }^{20}$. Esse comportamento é atribuido à diminuição na densidade eletrônica do sítio catalítico, favorecendo a inserção do estireno.

Os catalisadores de níquel com ligantes alílicos são utilizados na
Tabela 1. Efeito dos ligantes em catalisadores de níquel na polimerização de estireno ${ }^{19}$

\begin{tabular}{|c|c|c|c|}
\hline Catalisador & $\begin{array}{l}\text { Conversão } \\
(\%)\end{array}$ & $\begin{array}{c}\operatorname{Mw}\left(10^{-3}\right) \\
\mathrm{g} / \mathrm{mol}\end{array}$ & $\mathrm{Mw} / \mathrm{Mn}$ \\
\hline 1. $\mathrm{Ni}(\mathrm{acac})_{2}$ & 95 & 19 & 2,5 \\
\hline 2. $\mathrm{NiCl}_{2}$ & 99 & 19 & 2,0 \\
\hline 3. $\left[(\mathrm{EtO})_{3} \mathrm{P}\right]_{2} \mathrm{NiCl}_{2}$ & 65 & 18 & 2,3 \\
\hline 4. $\left(\mathrm{Et}_{3} \mathrm{P}\right)_{2} \mathrm{NiCl}_{2}$ & 24 & 18 & 2,2 \\
\hline 5. $\left(\mathrm{Cy}_{3} \mathrm{P}\right)_{2} \mathrm{NiCl}_{2}$ & 19 & 19 & 2,5 \\
\hline 6. $\left(\mathrm{iPr}_{3} \mathrm{P}\right)_{2} \mathrm{NiCl}_{2}$ & 11 & 9 & 4,1 \\
\hline 7. $\left(\Phi_{2} \mathrm{MeP}\right)_{2} \mathrm{NiCl}_{2}$ & 13 & 14 & 2,6 \\
\hline 8. $\left(\Phi_{2} \mathrm{MeP}\right)_{2} \mathrm{NiCl}_{2}$ & 9,5 & 18 & 8,9 \\
\hline 9. $\left(\Phi_{2} \mathrm{P}\right)_{2} \mathrm{NiCl}_{2}$ & 5,3 & 15 & 1,6 \\
\hline 10. $\left[\mathrm{Fe}\left(\mathrm{CpP} \Phi_{2}\right)_{2}\right] \mathrm{NiCl}_{2}$ & 0,7 & - & - \\
\hline 11. (phen) $\mathrm{NiCl}_{2}$ & 28 & 24 & 3,2 \\
\hline 12. $\mathrm{Cp}_{2} \mathrm{Ni}$ & 46 & 18 & 2,1 \\
\hline 13. $\mathrm{Ni}\left(\Phi_{2} \mathrm{C}_{2} \mathrm{~S}_{2}\right)_{2}$ & 0 & - & - \\
\hline 14. $\left[\left(\Phi_{2} \mathrm{PCH}_{2}\right)_{2} \mathrm{Py}\right] \mathrm{Ni}_{2}\left(\mathrm{ClO}_{4}\right)_{2} 2 \mathrm{CH}_{3} \mathrm{CN}$ & 9,1 & - & - \\
\hline 15. $\mathrm{Ni}\left[\mathrm{P}(\mathrm{OEt})_{3}\right]_{4}$ & 2,9 & 95 & 3,4 \\
\hline
\end{tabular}

acac $=$ acetilacetonato $; \mathrm{Cp}=$ ciclopentadienila $; \mathrm{Cy}=$ ciclo-hexila $; \mathrm{Et}=$ etila; $\mathrm{iPr}=$ isopropila; $\mathrm{Me}=$ metila; phen $=$ o-fenantrolina, $\mathrm{Py}=3,5-$ pyrazolila, $\Phi=$ fenila. Condições reacionais: $\mathrm{T}=50{ }^{\circ} \mathrm{C}$; Tempo de polimerização $=4 \mathrm{~h}$; Concentração de estireno $=2,6 \mathrm{~mol} / \mathrm{L}$; Razão molar $\mathrm{Al} / \mathrm{Ni}=50 . \mathrm{Mn}-$ peso molecular numérico médio; $\mathrm{Mw}-$ peso molecular ponderal médio; $\mathrm{Mw} / \mathrm{Mn}$ - distribuição de peso molecular.

Tabela 2. Efeito da acidez dos ligantes nos catalisadore ${ }^{20}$

\begin{tabular}{lcccc}
\hline Catalisador & $\begin{array}{c}\text { Conversão } \\
(\%)\end{array}$ & $\begin{array}{c}\mathrm{mmmm} \\
(\%)\end{array}$ & $\begin{array}{c}\mathrm{Mn}\left(10^{-3}\right) \\
\mathrm{g} / \mathrm{mol}\end{array}$ & $\mathrm{Mw} / \mathrm{Mn}$ \\
\hline $\mathrm{Ni}(\text { naph })_{2}$ & 100 & 50 & 14,0 & 1,5 \\
$\mathrm{Ni}(\mathrm{hfacac})_{2}$ & 100 & 52 & 9,9 & 1,6 \\
$\mathrm{Ni}(\text { acac })_{2}$ & 100 & 43 & 9,0 & 1,4 \\
\hline
\end{tabular}

naph - $\alpha$-nitro-acetofenona; hfacac - hexa-flúoroacetilacetona; mmmm - pêntades, determinado por RMN; Mn - peso molecular numérico médio; $\mathrm{Mw}$ - peso molecular ponderal médio; $\mathrm{Mw} / \mathrm{Mn}$ distribuição de peso molecular.

oligomerização de estireno ${ }^{21,22}$ e produzem poliestireno com teor de tríades isotáticas (mm) em torno de $43 \%$. A adição de algumas bases de Lewis, tais como fosfinas, aumenta a atividade desses catalisadores. No entanto, bases como tiofeno e tetra-hidrofurano ao serem adicionadas ao sistema catalítico acetilacetonato de níquel/metilaluminoxano ${ }^{23}$ diminuem sua atividade, devido à coordenação irreversível dessas bases com o sítio ativo. Embora a trietilamina e a triciclohexilfosfina também levem à diminuição da atividade, o poliestireno obtido em presença dessas bases é altamente isotático, com temperatura de fusão de $220^{\circ} \mathrm{C}$.

\section{Efeito do suporte}

A utilização de sílica e alumina como suportes para o acetilacetonato de níquel na polimerização de estireno é útil na formação de polímeros com maior isotaticidade e peso molecular ${ }^{24-26}$. A Tabela 3 mostra que o acetilacetonato de níquel suportado em sílica, ou em sílica pré-tratada com metilaluminoxano, pode ser ativado com metilaluminoxano e, diferentemente do sistema homogêneo, mostra-se ativo na presença de alquilalumínio. Esse resultado pode ser atribuído à interação do níquel com o oxigênio na superfície da sílica (Figura 3), ou então, ao complexo coroa formado entre o metilalumi- 
noxano e o complexo de níquel. Ambos os efeitos levariam à estabilização do sítio catiônico formado na presença do alquílalumínio ${ }^{5-7}$.

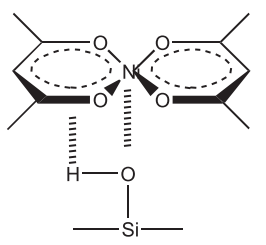

Figura 3. Estrutura do catalisador $\mathrm{SiO}_{2} / \mathrm{Ni}(\text { acac })_{2}{ }^{37}$

\section{Efeito do cocatalisador}

O cocatalisador metilaluminoxano é um dos principais responsáveis pela atividade do acetilacetonato de níquel, pois compostos de alquilalumínio comuns (por exemplo, trimetilalumínio, trietilalumínio, triisobutilalumínio) sozinhos, não são capazes de ativá-lo para a polimerização de estireno. O metilaluminoxano utilizado na ativação do acetilacetonato de níquel pode ser previamente tratado para eliminar parte do trimetilalumínio residual. Esse tratamento pode ser feito por dois métodos. Um deles consiste na destilação do solvente, junto com trimetilalumínio residual, e o outro, na precipitação do metilaluminoxano com hexano. O metilaluminoxano, assim tratado, pode levar ao aumento na atividade de catalisadores à base de níquel ${ }^{20,23}$ (Tabela 4, experimentos 1, 2 e 3).

A taticidade dos polímeros produzidos é geralmente avaliada através de espectroscopia de RMN de ${ }^{13} \mathrm{C}$. Os sinais de ressonância em 146,3 ppm e em 146,1 ppm referem-se, respectivamente, às pêntades $\mathrm{mmmm}$ e $\mathrm{mmmr}$, enquanto as seqüências atática e sindiotática são observadas através de sinais na faixa de 146 a 145 ppm, respectivamente. As análises de $\mathrm{RMN}$ de ${ }^{13} \mathrm{C}$ mostram que a isotaticidade aumenta quando se utiliza metilaluminoxano pré-trata- do. A utilização de metilaluminoxano comercial, de dois diferentes fornecedores (Akzo e Witco), para ativar o acetilacetonato de níquel suportado em sílica pré-tratada com metilaluminoxano mostrou que o metilaluminoxano (Akzo) apresenta melhor performance como cocatalisador que o metilaluminoxano (Witco) ${ }^{25}$ (Tabela 4 experimentos 4 e 5). Esse comportamento pode ser explicado pelo maior peso molecular do metilaluminoxano (Akzo), que acelera a formação de sítios ativos.

Diversos estudos mostram que o trimetilalumínio residual pode degradar as moléculas de metilaluminoxano, dando origem a moléculas de metilaluminoxano com menor peso molecular ${ }^{38}$. Além disso, Zakharov e colaboradores ${ }^{39,40}$, com base em resultados de simulação por DFT ("Density functional theory"), propuseram um mecanismo de formação da espécie reativa de metilaluminoxano, responsável pela ativação do catalisador (Figura 4). O mecanismo está baseado na interação do dímero do trimetilalumínio com o metilaluminoxano, que leva à formação da estrutura II, seguido da formação da estrutura III de maior acidez, que atua como cocatalisador. Nesse mecanismo, três aspectos são importantes: (a) as duas moléculas de trimetilalumínio estão associadas aos centros ácidos $(\mathrm{Al})$ e básicos $(\mathrm{O})$ do metilaluminoxano (Estrutura II); (b) a formação da espécie reativa (III) é favorecida, quando a energia de dimerização do trimetilalumínio se iguala à energia de ligação do trimetilalumínio com metilaluminoxano e (c) o aumento no peso molecular do metilaluminoxano favorece o deslocamento do equilíbrio para a formação da espécie reativa (III). Dessa maneira, a retirada de trimetilalumínio ou então o

$\mathrm{Al}_{2} \mathrm{Me}_{6}+\underset{\mathrm{I}}{\mathrm{MAO}} \stackrel{(1)}{\rightleftharpoons} \mathrm{AlMe}_{3}-\underset{\text { II }}{\mathrm{MAO}}-\mathrm{AlMe}_{3} \stackrel{(2)}{\rightleftharpoons} \mathrm{Al}_{2} \mathrm{Me}_{6}+\underset{\text { III }}{\longrightarrow}-\underset{\text { MAO }}{\rightleftharpoons}$

Figura 4. Mecanismo de formação da espécie reativa do metilaluminoxano $(M A O)^{40}$

Tabela 3. Polimerização de estireno sobre $\mathrm{Ni}(\mathrm{acac})_{2}$ suportado em $\mathrm{SiO}_{2}$ a) 24

\begin{tabular}{|c|c|c|c|c|c|}
\hline \multirow[t]{2}{*}{ Catalisador } & \multicolumn{2}{|c|}{ Cocatalisador } & \multirow[b]{2}{*}{ Massa (g) } & \multirow[b]{2}{*}{$\operatorname{Mw}\left(10^{-4}\right)(\mathrm{g} / \mathrm{mol})$} & \multirow[b]{2}{*}{$\mathrm{Mw} / \mathrm{Mn}$} \\
\hline & Tipo & mmol & & & \\
\hline \multirow[t]{6}{*}{$\mathrm{SiO}_{2} / \mathrm{Ni}(\mathrm{acac})_{2}$} & $\mathrm{MAO}$ & 1,6 & 1,95 & 2,69 & 1,8 \\
\hline & MAO & 2,6 & 2,72 & 2,38 & 1,7 \\
\hline & MAO & 12,9 & 4,22 & 3,27 & 1,8 \\
\hline & MAO & 12,9 & 4,44 & 2,55 & 2,9 \\
\hline & $\mathrm{Al}(\mathrm{Et})_{3}^{\mathrm{b})}$ & 2,6 & 0,45 & 0,86 & 1,7 \\
\hline & $\left.\mathrm{Al}(\mathrm{iBu})_{3}{ }^{\mathrm{b}}\right)$ & 2,6 & 0,36 & nd & nd \\
\hline \multirow{3}{*}{$\mathrm{SiO}_{2} / \mathrm{MAO} / \mathrm{Ni}(\mathrm{acac})_{2}$} & $\mathrm{MAO}$ & 12,9 & 3,58 & 2,96 & 1,8 \\
\hline & $\mathrm{Al}(\mathrm{Et})_{3}$ & 1,3 & 0,14 & nd & nd \\
\hline & $\mathrm{Al}(\mathrm{Et})_{3}$ & 2,6 & 0 & nd & nd \\
\hline
\end{tabular}

a) Condições de polimerização: $20 \mathrm{~mL}$ de tolueno; 43,5 mmol de estireno; 0,025 mmol de $\mathrm{Ni}, \mathrm{T}=35^{\circ} \mathrm{C}$; $\mathrm{t}=24 \mathrm{~h}$; nd - não determinado; $\mathrm{MAO}$ - metilaluminoxano; Mn - peso molecular numérico médio; Mw - peso molecular ponderal médio; Mw/Mn - distribuição de peso molecular.

b) Solvente de polimerização= isooctano.

Tabela 4. Efeito da presença de TMA na atividade catalítica dos sistemas homogêneo e heterogêneo ${ }^{23,25}$

\begin{tabular}{|c|c|c|c|c|c|c|c|}
\hline $\mathrm{N}^{\circ}$ & Catalisador & Catalisador mmol & Tipo de MAO & $\mathrm{Al} / \mathrm{Ni}$ & Temp. $\left({ }^{\circ} \mathrm{C}\right)$ & Tempo (h) & Conversão (\%) \\
\hline 1 & $\mathrm{Ni}(\mathrm{acac})_{2}$ & 0,05 & MAO W & 30 & 20 & 4 & 38 \\
\hline 2 & $\mathrm{Ni}(\mathrm{acac})_{2}$ & 0,05 & MAO D & 30 & 20 & 4 & 91 \\
\hline 3 & $\mathrm{Ni}(\mathrm{acac})_{2}^{2}$ & 0,05 & MAO P & 30 & 20 & 4 & 91 \\
\hline 4 & $\mathrm{Ni}(\mathrm{acac})_{2} / \mathrm{MAO} / \mathrm{SiO}_{2}$ & 0,002 & MAO (Akzo) & 200 & 40 & 24 & 87 \\
\hline 5 & $\mathrm{Ni}(\mathrm{acac})_{2} / \mathrm{MAO} / \mathrm{SiO}_{2}$ & 0,002 & MAO (Witco) & 200 & 40 & 24 & 7 \\
\hline
\end{tabular}


emprego de metilaluminoxano com maior peso molecular colaboram para o aumento da atividade do catalisador.

Além do trimetilalumínio, outros compostos alquilalumínio também podem influenciar o comportamento do metilaluminoxano como cocatalisador. Um exemplo é o triisobutilalumínio(TIBA ${ }^{26}$, que foi adicionado em teor constante $(\mathrm{TIBA} / \mathrm{Ni}=5)$ em um estudo sobre a influência da concentração do metilaluminoxano, utilizando-se o sistema heterogêneo acetilacetonato de níquel/metilaluminoxano/sílica (Tabela 5). O catalisador, ativado apenas com metilaluminoxano, mostrou uma queda de atividade em razões molares $\mathrm{Al} / \mathrm{Ni}$ superiores a 200. Esse comportamento pode ser explicado por meio de reações de sobrerredução, que levam à formação de espécies de $\mathrm{Ni}(0)$, não ativas na polimerização de estireno ${ }^{19}$. No entanto, o catalisador ativado com metilaluminoxano na presença de triisobutilalumínio não apresenta máximo de atividade. Esse resultado pode ser atribuído à troca do trimetilalumínio associado ao metilaluminoxano por triisobutilalumínio ${ }^{43}$ ou à troca de grupos metilas ligados ao metilaluminoxano por grupamentos isobutila do triisobutilalumínio ${ }^{44}$. Ambas as hipóteses levariam à formação de um aluminoxano cercado por grupamentos metila e isobutila, modificando o seu poder alquilante e, assim, a sua capacidade de estabilizar os sítios ativos.

$\mathrm{O}$ aumento da concentração de metilaluminoxano na presença de triisobutilalumínio provoca o aumento do teor de tríades isotáticas (mm). Esse comportamento não é observado quando se utiliza apenas metilaluminoxano como cocatalisador. Outros autores sugeriram que o triisobutilalumínio poderia modificar a esfera de coordenação dos sítios ativos ${ }^{42-44}$. Nesse caso, a presença do triisobutilalumínio poderia inibir a formação do grupamento benzílico $\left(\eta^{3}\right)$, responsável pela estereoespecificidade do catalisador.

\section{MECANISMO DE POLIMERIZAÇÃO}

O mecanismo de ativação dos catalisadores de coordenação, de forma geral, já é conhecido na literatura ${ }^{1-15}$ e compreende as etapas de iniciação, propagação e transferência de cadeia, que pode ocorrer com o metilaluminoxano, com o monômero ou ser espontânea.

\section{Iniciação: formação das espécies ativas}

No caso dos catalisadores de níquel(II) para a polimerização de estireno, a natureza dos ligantes no sítio ativo alquilado, resultante da ativação com metilaluminoxano, não é bem conhecida, assim como a natureza da polimerização (homogênea ou heterogênea).
Sabe-se que o acetilacetonato reage com alquilalumínio formando um gel, que também pode ser observado nas polimerizações ativadas com metilaluminoxano ${ }^{45,46}$. Com base nesse comportamento, foi sugerida a presença de sítios ativos adsorvidos em matriz heterogênea ${ }^{19}$.

Alguns aspectos em relação à presença de sítios múltiplos têm sido alvo de estudos de vários pesquisadores ${ }^{20,23}$. Porri e colaboradores $^{23}$ estudaram as frações insolúveis de poliestireno em metil etil cetona obtido com acetilacetonato de níquel. Os autores notaram que em razões molares $\mathrm{Al} / \mathrm{Ni}$ mais baixas $(\mathrm{Al} / \mathrm{Ni}=30)$ se formava a maior proporção de sítios ativos isoespecíficos, que diminuía com o aumento dessa razão molar. As frações solúveis possuíam menor peso molecular e menor isotaticidade. Carreti ${ }^{20}$, por sua vez, obteve os mesmos resultados quanto à isotaticidade e peso molecular. No entanto, sugeriu que os sítios se diferenciavam apenas no tempo de estabilização e na evolução de sua produtividade.

Estudos sobre a ordem de adição dos reagentes, realizados por Ribeiro e colaboradores ${ }^{27}$, mostraram diferenças entre os dois métodos utilizados, isto é, adição do acetilacetonato de níquel seguido do metilaluminoxano e ativação do acetilacetonato de níquel com metilaluminoxano conduzida na presença do estireno. A atividade catalítica foi mais alta quando se utilizou o segundo método. A estabilização dos sítios ativos, evitando a decomposição ou desativação irreversível, e o aumento da complexação do monômero com sítio ativo podem explicar esse comportamento. Notou-se o mesmo comportamento na homopolimerização de norborneno, butadieno e copolimerização de estireno com norborneno ${ }^{27,28}$.

\section{Propagação}

Há um consenso entre vários autores de que o mecanismo de polimerização de estireno com catalisadores de níquel ocorre por meio da coordenação com o metal ${ }^{21-23,25,26}$. Ascenso ${ }^{21,22}$ propôs um equilíbrio entre duas espécies $\eta^{1}$ e $\eta^{3}$ formadas no final da cadeia em propagação. As espécies $\eta^{3}$ são responsáveis pela isoespecificidade da inserção do estireno. A confirmação da existência da espécie $\eta^{3}$ foi possível através de seu isolamento em baixas temperaturas $\left(-10{ }^{\circ} \mathrm{C}\right)^{22}$. A distribuição das tríades isotáticas, atáticas e sindiotáticas do poliestireno, obtido com acetilacetonato de níquel com sistemas homogêneo e heterogêneo ativados com metilaluminoxano ${ }^{25}$, segue o modelo de Markov de $1^{\text {a }}$ ordem. Esse resultado confirma o controle isoespecífico por meio da estereoquímica da unidade final da cadeia em propagação.

Tabela 5. Avaliação da influência de triisobutilalumínio (TIBA) na ativação do sistema $\mathrm{Ni}(\mathrm{acac})_{2} / \mathrm{MAO} / \mathrm{SiO}_{2} \mathrm{com}$ metilaluminoxano ${ }^{26}$

\begin{tabular}{|c|c|c|c|c|c|c|}
\hline $\mathrm{N}^{\circ}$ & Razão molar Al(MAO)/Ni & TIBA/Ni & Atividade (kgPS/molNi*h) & $\mathrm{mm}(\%)$ & $\operatorname{mr}(\%)$ & $\operatorname{rr}(\%)$ \\
\hline \multicolumn{7}{|c|}{ Catalisador ativado com MAO } \\
\hline 1 & 50 & 0 & 14,5 & 55 & 36 & 9 \\
\hline 2 & 200 & 0 & 83,3 & 47 & 48 & 5 \\
\hline 3 & 500 & 0 & 57,7 & nd & nd & nd \\
\hline \multicolumn{7}{|c|}{ Catalisador ativado com MAO e TIBA } \\
\hline 4 & 0 & 5 & 5,4 & 53 & 43 & 4 \\
\hline 5 & 45 & 5 & 4,0 & 32 & 61 & 7 \\
\hline 6 & 195 & 5 & 10,5 & 46 & 50 & 4 \\
\hline 7 & 495 & 5 & 41,6 & 58 & 39 & 3 \\
\hline 8 & 695 & 5 & 84,4 & 59 & 38 & 3 \\
\hline 9 & 995 & 5 & 84,4 & 59 & 38 & 3 \\
\hline
\end{tabular}

$\overline{\mathrm{nd}}$ - não determinada; $(\mathrm{mm}=$ tríades isotáticas; $\mathrm{mr}=$ tríades atáticas; $\mathrm{rr}=$ tríades sindiotáticas $)$ obtidos por $\mathrm{RMN}$ de ${ }^{13} \mathrm{C} ; \mathrm{MAO}-$ metilaluminoxano; PS - poliestireno 


\section{Terminação e transferência de cadeia}

Os principais fatores responsáveis pelo alargamento da distribuição do peso molecular são a presença de vários sítios catalíticos, incluindo aqueles responsáveis pela iniciação iônica ou radicalar e a ocorrência de reações de terminação e transferência de cadeia. As terminações de cadeia ocorrem apenas no momento em que doadores de prótons são adicionados no meio da polimerização.

A principal reação de transferência de cadeia que ocorre com os catalisadores de níquel, é a eliminação de hidrogênio $\beta$, observada por Ascenso ${ }^{21,22}$ com catalisadores de níquel contendo ligantes alílicos. A eliminação de hidrogênio $\beta$ é comprovada através da avaliação das terminações de cadeia ( $\mathrm{PhCH}-\mathrm{CH}_{2}-\mathrm{PhCH}-\mathrm{CH}_{3}$ ) resultante da inserção do monômero na ligação $\mathrm{Ni}-\mathrm{H}$ e $(-\mathrm{CH}-\mathrm{PhCH}-\mathrm{CH}=$ $\mathrm{PhCH}$ ) resultantes da reação de eliminação de hidrogênio $\beta$, ambas observadas por RMN de ${ }^{13} \mathrm{C}$.

\section{EFEITO DOS PARÂMETROS REACIONAIS}

Os parâmetros reacionais são discutidos na literatura com muita frequiência devido a sua importância na determinação das principais características dos polímeros formados: peso molecular, polidispersão e microestrutura, bem como na determinação do desempenho do catalisador. A avaliação desses parâmetros com catalisadores de níquel já foi realizada tanto no sistema homogêneo como no heterogêneo. A seguir serão apresentados e discutidos os principais parâmetros reacionais: razão molar $\mathrm{Al} / \mathrm{Ni}$, temperatura, concentração de catalisador, tempo de polimerização e envelhecimento do catalisador.

\section{Efeito da razão molar $\mathrm{Al} / \mathrm{Ni}$}

As diferentes razões molares mínimas observadas na literatura para ativar o catalisador podem estar relacionadas ao tipo de metilaluminoxano ou à concentração de catalisador ${ }^{23,25}$. A atividade catalítica aumenta rapidamente a partir da razão molar em que o catalisador se torna ativo. Resultados obtidos em um intervalo de razão molar $\mathrm{Al} / \mathrm{Ni}$ de 50 a 500 mostram um máximo de atividade entre a razão 100 e 200 e uma queda posterior, possivelmente, devido à desativação do catalisador por meio de reações de sobrerredução ${ }^{25}$.

Com relação ao efeito da razão molar $\mathrm{Al} / \mathrm{Ni}$ sobre a microestrutura do polímero, o aumento da concentração de metilaluminoxano provoca um decréscimo no teor de tríades isotáticas $(\mathrm{mm})$ enquanto que a macroestutura, peso molecular e a distribuição de peso molecular não são afetados (Tabela 6) (19,25 $^{10}$

\section{Efeito da temperatura}

Diferentes comportamentos foram observados em relação à variação da temperatura de polimerização. Pó e colaboradores ${ }^{19}$ perceberam que o peso molecular do poliestireno obtido com acetilacetonato de níquel diminuía com o aumento da temperatura de polimerização, entre 25 e $75^{\circ} \mathrm{C}$, enquanto que a polidispersão não variava e o teor de tríades isotáticas aumentava com a diminuição da temperatura de polimerização. Esse comportamento pode ser explicado pelo maior tempo de vida da espécie $\eta^{3}$ durante a propagação ${ }^{23,25}$. Entretanto, há resultados que não corroboram essas observações, notando-se um máximo de conversão em $40{ }^{\circ} \mathrm{C}$, com uma queda posterior, certamente devido a reações de desativação do catalisador ${ }^{25}$, quando o estudo foi realizado entre 30 e $50{ }^{\circ} \mathrm{C}$.

\section{Efeito da concentração de catalisador}

A atividade catalítica dos complexos de níquel apresenta um máximo de atividade em um determinado valor de concentração de catalisador, que é dependente das condições reacionais. Esse comportamento pode ser atribuído à desativação dos sítios pela formação de espécies bimoleculares de níquel não ativas na polimerização de estireno ${ }^{19,21-23,25}$. Observou-se que a diminuição do peso molecular com o aumento da concentração do catalisador é causada por dois fatores: o efeito de diluição que favorece a dissociação dos sítios ativos, acelerando assim a propagação de cadeia e a formação de espécies bimoleculares inativas entre o sítio ativo e o acetilacetonato de níquel, interrompendo a propagação de cadeia ${ }^{19,21-23,25}$.

\section{Efeito do tempo de polimerização e envelhecimento do catalisador heterogêneo}

No sistema catalítico homogêneo, utilizando metilaluminoxano produzido pela Witco [MAO(witco)], a atividade catalítica permanece constante nas primeiras $4 \mathrm{~h}$ e a partir deste tempo, aumenta com o tempo de polimerização (Figura 5) ${ }^{25}$. Para explicar este comportamento, foi sugerido que é necessário um tempo de indução para que ocorra a formação de espécies ativas para polimerização.

$\mathrm{O}$ efeito do tempo de polimerização e de envelhecimento na atividade do sistema heterogêneo acetilacetonato de níquel/ metilaluminoxano/sílica é mostrado na Figura 5. O aumento do tempo de polimerização leva à desativação de sítios ativos, o que reduz a atividade do sistema heterogêneo. A desativação bimolecular, que ocorre no sistema homogêneo, é inibida no sistema heterogêneo de-

Tabela 6. Efeito de parâmetros reacionais na polimerização de estireno com o sistema catalítico $\mathrm{Ni}(\mathrm{acac})_{2} / \mathrm{MAO}^{19,25}$

\begin{tabular}{|c|c|c|c|c|c|c|c|c|}
\hline Temp $\left({ }^{\circ} \mathrm{C}\right)$ & [Ni] mmol & Razão Al/Ni & Conversão (\%) & $\mathrm{mm}(\%)$ & $\mathrm{mr}(\%)$ & $\operatorname{rr}(\%)$ & $\mathrm{Mw}\left(10^{-4}\right) \mathrm{g} / \mathrm{mol}$ & $\mathrm{Mw} / \mathrm{Mn}$ \\
\hline 26 & 0,002 & 50 & 7 & 56 & 43 & 1 & nd & nd \\
\hline 40 & 0,002 & 50 & 19 & 50 & 45 & 5 & 3,9 & 2,4 \\
\hline 40 & 0,002 & 100 & 50 & 50 & 45 & 5 & 3,9 & 2,4 \\
\hline 40 & 0,002 & 300 & 50 & 48 & 47 & 5 & 3,8 & 2,4 \\
\hline 50 & 0,002 & 50 & 2 & nd & nd & nd & nd & nd \\
\hline $25^{\mathrm{a}}$ & 0,09 & 50 & 98 & nd & nd & nd & 2,6 & 2,2 \\
\hline $70^{\mathrm{a}}$ & 0,09 & 50 & 95 & nd & nd & nd & 1,9 & 2,5 \\
\hline $90^{\mathrm{a}}$ & 0,09 & 50 & 88 & nd & nd & nd & 1,5 & 2,4 \\
\hline
\end{tabular}

a) Polimerização em massa ${ }^{19}$; nd - não determinado; $(\mathrm{mm}$ - tríades isotáticas; $\mathrm{mr}$ = tríades atáticas; $\mathrm{rr}$ = tríades sindiotáticas $)$ obtidas por RMN de ${ }^{13} \mathrm{C} ; \mathrm{Mw}$ - peso molecular ponderal médio; Mw/Mn - distribuição de peso molecular; $\mathrm{Ni}(\mathrm{acac})_{2}$ - acetilacetonato de níquel. 
vido ao efeito de isolamento dos sítios na superfície do suporte, aumentando assim a atividade catalítica do sistema heterogêneo. A queda da atividade com o tempo de envelhecimento sugere a ocorrência de reações irreversíveis de desativação (Figura 6).

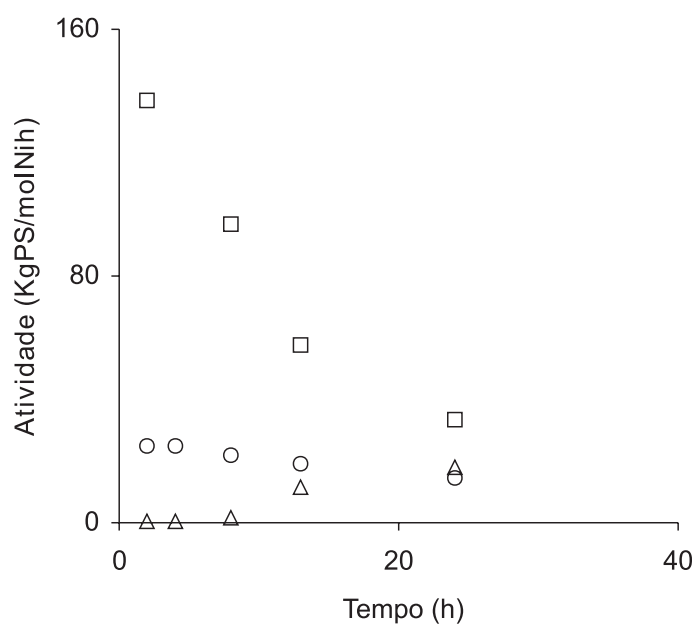

Figura 5. Efeito do tempo de polimerização no sistema heterogêneo $\mathrm{Ni}(\text { acac) })_{2} / \mathrm{MAO} / S i O_{2}:(\square)$ sem envelhecimento [MAO(Akzo)]; (O) com tempo de envelhecimento de 14 dias; $(\triangle)$ sistema homogêneo $[M A O(\text { Witco })]^{25}$
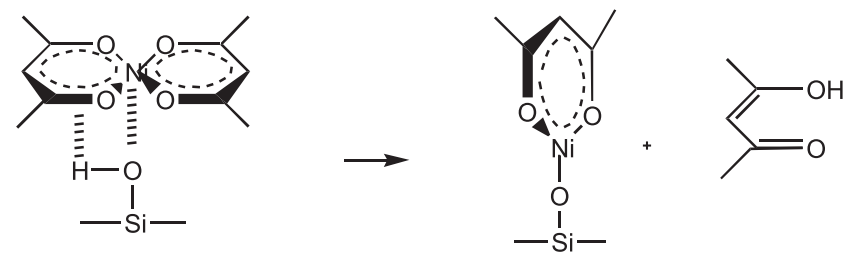

Figura 6. Reação entre o acetilacetonato de níquel e a hidroxila da sílica ${ }^{37}$

\section{COPOLIMERIZAÇÃO DE ESTIRENO COM ETILENO}

Os catalisadores de níquel podem copolimerizar estireno com etileno, dando origem a copolímeros alternados ou aleatórios ${ }^{20}$. O espectro de $\mathrm{RMN}$ de ${ }^{13} \mathrm{C}$ do polímero obtido com bis-( $\alpha$-nitroacetofenona) de níquel(II) permite identificar um sinal intenso em 29,7 ppm atribuído ao metileno da longa seqüência de polimetileno. Esse sinal é também confirmado pelos sinais em 27,2 ppm atribuído ao grupo metileno na posição $ß$ ao carbono terciário na cadeia polimérica, assim como pelo sinal 37 ppm atribuído ao metileno situado na posição $\alpha$ em relação a esse mesmo carbono. Nota-se também a presença de dois sinais em 40,4 e 43 ppm atribuídos a carbonos terciários separados por um metileno. A ausência de sinais em 25 e 45 ppm, que são característicos da presença de copolímero alternado, indica que o copolímero possui uma distribuição de unidades repetitivas em bloco (25). O espectro de $\mathrm{RMN}$ de ${ }^{13} \mathrm{C}$ do copolímero obtido com acetilacetonato de níquel mostra os mesmos sinais em 29,7, 27,2 e 37 ppm. O sinal em 41 ppm corresponde ao carbono terciário adjacente a blocos longos de etileno. O polímero caracteriza-se por apresentar unidades de estireno isoladas.

\section{COPOLIMERIZAÇÃO DE ESTIRENO COM NORBORNENO}

O estudo da copolimerização de estireno com norborneno, por Ribeiro e colaboradores ${ }^{27}$, mostrou que o aumento na concentração de estireno diminui a atividade catalítica do acetilacetonato de níquel ativado com metilaluminoxano. O mecanismo de Ystenes foi utilizado para interpretar esse comportamento ${ }^{27}$. De acordo com este mecanismo, o sítio ativo nunca está livre, mas sempre ocupado por uma molécula de monômero complexada que, por sua vez, irá se inserir na cadeia polimérica apenas quando outra molécula de monômero estiver pronta para se complexar.

No caso da copolimerização de estireno com norborneno, a razão de incorporação do norborneno na cadeia polimérica é bem maior que a do estireno. $\mathrm{O}$ aumento da concentração de estireno favorece ligeiramente a complexação e inserção do estireno na cadeia polimérica. Devido à dificuldade do estireno em se complexar com o sítio ativo e forçar a inserção do norboneno (mecanismo de Ystenes), o teor de estireno incorporado é menor do que o usado na alimentação. Além disso, ocorre um decréscimo na atividade catalítica ${ }^{27}$.

A queda na atividade, com a adição de uma pequena quantidade de norborneno, pode ser atribuída à complexação preferencial do norborneno, que está em baixas concentrações, e à baixa capacidade do estireno em se complexar e forçar a inserção do norborneno, provocando assim o decréscimo da atividade ${ }^{27}$.

O peso molecular do copolímero de estireno e norborneno diminui à medida que o estireno é adicionado à polimerização. Nesse caso, foi sugerida a presença de reações de transferência de cadeia para o estireno, o que leva a diminuição do peso molecular do copolímero $^{10}$.

Os copolímeros de estireno e norboneno, homopolímero de estireno e de norboneno obtidos foram caracterizados por RMN de ${ }^{1} \mathrm{H}$. O espectro do poliestireno apresentou um sinal em 6,5 ppm atribuído aos prótons na posição orto e um outro sinal em 7,0 ppm atribuído aos prótons na posição meta e para. O espectro dos copolímeros, com uma fração molar de estireno na alimentação menor que $50 \%$, mostrou apenas um sinal em 7,0 ppm, indicando que não existem blocos com mais de oito unidades de estireno. Dessa forma, o copolímero possui uma distribuição aleatória com unidades de estireno isoladas. $\mathrm{O}$ espectro da amostra, com mais de $50 \%$ de estireno na alimentação, apresentou dois picos, um em 6,5 ppm e outro em 7,0 ppm, indicativos da presença de blocos com mais de oito unidades estirênicas.

\section{COPOLIMERIZAÇÃO DE ESTIRENO COM DIENOS CONJUGADOS}

Vários catalisadores com ligantes acetilacetonato já foram testados na copolimerização de estireno com dienos conjugados. $\mathrm{O}$ acetilacetonato de níquel destaca-se pela alta atividade catalítica, pela alta incorporação de estireno e pelo controle da microestrutura do dieno inserido na cadeia polimérica ${ }^{29-31}$.

\section{Copolimerização de estireno e isopreno}

Endo e colaboradore ${ }^{29-31}$ avaliaram a copolimerização do estireno com isopreno com diferentes concentrações de estireno na alimentação (Tabela 7). Como a polidispersão dos polímeros ficou em torno de dois, os autores propuseram que as copolimerizações ocorriam por meio de um sítio único, sem a formação de homopolímeros. Os copolímeros apresentaram microestrutura com predominância de unidades cis-1,4 e ausência de unidades 1,2. O teor de unidades cis1,4 diminuiu com o aumento da concentração de estireno na alimentação. Nesse caso, o controle da microestrutura do isopreno pode ser explicado pelo mecanismo conhecido como "back-biting", proposto por Kobayashi para polimerização de butadieno ${ }^{48}$. Esse mecanismo propõe que a penúltima unidade de dieno incorporada está coordenada ao centro metálico, aspecto importante no processo de inserção 
Tabela 7. Copolimerização de estireno e isopreno com o sistema catalítico $\mathrm{Ni}(\mathrm{acac})_{2} / \mathrm{MAO}^{\mathrm{a} 28}$

\begin{tabular}{|c|c|c|c|c|c|c|}
\hline [St] na alimentação (\%) & Conversão (\%) & $\operatorname{Mn}\left(10^{-3}\right)$ & $\mathrm{Mw} / \mathrm{Mn}$ & $\operatorname{cis}-1,4^{\mathrm{a}}$ & $\operatorname{trans}-1,4^{\mathrm{a}}$ & $3,4^{\mathrm{a}}$ \\
\hline 0 & 7,0 & 13,0 & 2,0 & 85,8 & 7,2 & 7,0 \\
\hline 20 & 2,6 & 4,8 & 2,0 & 83,2 & 10,5 & 6,3 \\
\hline 40 & 3,3 & 5,0 & 2,0 & 81,3 & 13,5 & 5,2 \\
\hline 50 & 5,7 & 5,3 & 1,9 & 79,1 & 16,4 & 4,5 \\
\hline 50 & 24,2 & 15,2 & 2,0 & 80,7 & 13,0 & 6,3 \\
\hline 60 & 7,7 & 5,6 & 2,0 & 76,5 & 19,2 & 4,3 \\
\hline 80 & 16,7 & 6,9 & 2,2 & 70,5 & 23,5 & 6,0 \\
\hline 100 & 35,8 & 31,7 & 2,1 & nd & nd & nd \\
\hline
\end{tabular}

nd = não determinado; a = determinado por IV; $\mathrm{St}=$ estireno; $\mathrm{Mn}=$ peso molecular numérico médio; Mw= peso molecular ponderal médio; $\mathrm{Mw} / \mathrm{Mn}=$ distribuição de peso molecular

cis-1,4. No caso da copolimerização, a presença do estireno como penúltima unidade incorporada faz com que a última unidade de isopreno tenha a configuração trans-1,4.

Foram avaliadas curvas de composição de estireno no copolímero versus concentração de estireno na alimentação, utilizando três diferentes sistemas iniciadores de polimerização, acetilacetonato de níquel, peróxido de benzoíla e butil-lítio (Figura 7). As curvas com peróxido de benzoíla e acetilacetonato de níquel foram bastante semelhantes e diferem da curva 3 , descartando assim um possível mecanismo aniônico. Dessa forma, foi proposto um mecanismo radicalar para explicar esses resultados. No entanto, um mecanismo via coordenação também deve ser considerado dado o controle estereoespecífico do catalisador ${ }^{29,30}$.

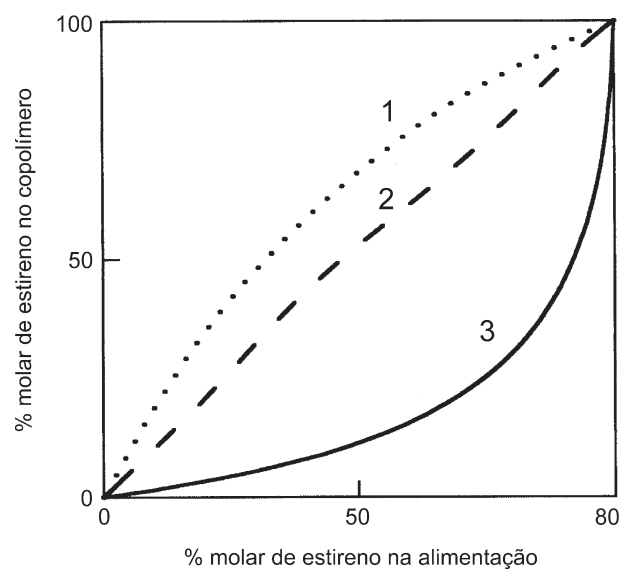

Figura 7. Curvas de composição dos copolímeros de estireno-isopreno obtidos com peróxido de benzoíla (1), Ni(acac)z MAO (2) e n-BuLi (3) ${ }^{29}$

As razões de reatividade para o estireno $\left(\mathrm{r}_{1}\right)$ e para o butadieno $\left(r_{2}\right)$ são 1,18 e 0,88 , respectivamente. O produto $r_{1} * r_{2}$ igual a 1,04 é indicativo de que a copolimerização ocorre de forma aleatória ${ }^{29}$.

\section{Copolimerização de estireno com butadieno}

Endo e colaboradores ${ }^{31}$ notaram que a atividade do acetilacetonato de níquel, na copolimerização de estireno com butadieno, diminui com o aumento da concentração de estireno na alimentação. Esse resultado é diferente daquele obtido com isopreno e mostra que o estireno se complexa preferencialmente com o sítio ativo em relação ao butadieno. A diminuição do peso molecular pela presença de estireno está ligada à ação do estireno como agente de transferência de cadeia na copolimerizações. A polidispersão em torno de dois permitiu sugerir que a copolimerização ocorre em sítio único, sem a formação de homopolímeros (Tabela 8$)^{31}$.

Tabela 8. Copolímeros de estireno com butadieno ${ }^{31}$

\begin{tabular}{cccc}
\hline $\begin{array}{c}\text { Estireno na alimentação } \\
(\mathrm{mol} \mathrm{\% )})\end{array}$ & $\begin{array}{c}\text { Conversão } \\
(\%)\end{array}$ & $\begin{array}{c}\mathrm{Mn}\left(10^{-3}\right) \\
\mathrm{g} / \mathrm{mol}\end{array}$ & $\mathrm{Mw} / \mathrm{Mn}$ \\
\hline 0 & 88,4 & 21,0 & 2,26 \\
20 & 34,9 & 5,7 & 1,78 \\
40 & 19,0 & 3,1 & 1,85 \\
50 & 12,8 & 3,1 & 1,64 \\
60 & 8,8 & 3,1 & 1,46 \\
80 & 5,9 & 2,7 & 1,88 \\
100 & 85,0 & 18,0 & 2,40
\end{tabular}

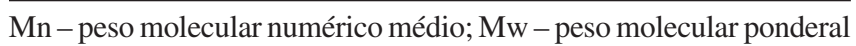
médio; Mw/Mn - distribuição de peso molecular.

A microestrutura dos copolímeros de butadieno - estireno não foi influenciada pela concentração de estireno na alimentação. Entretanto, um resultado diferente foi observado quando isopreno foi utilizado comonômero. Para efeito de comparação foram avaliadas também as copolimerizações via mecanismo radicalar usando 2,2'azobisisobutironitrila (AIBN) e aniônica utilizando butil-lítio. Curvas dessas reações são bastante diferentes da curva com acetilacetonato de níquel, indicando um possível mecanismo por coordenação (Figura 8).

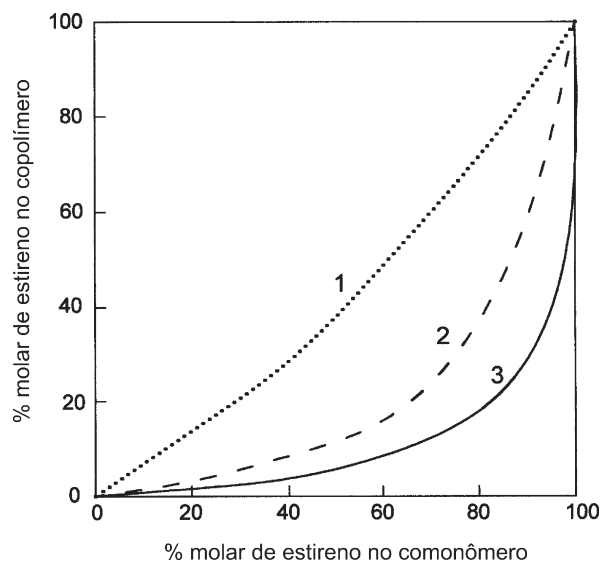

Figura 8. Curvas de teor de estireno no copolímero versus teor de estireno na alimentação utilizando como iniciadores (1) AIBN; (2) Ni(acac) 2 IMAO; (3) $n-B u L i^{31}$ 
As razões de reatividade para o estireno e butadieno são 0,07 e 3,6, respectivamente. O produto desses valores é igual a 0,27 , o que indica a possibilidade de ocorrência de uma copolimerização alternada ${ }^{31}$.

\section{COPOLIMERIZAÇÃO DE ESTIRENO COM METACRILATO DE METILA}

Uma das principais características do acetilacetonato de níquel é sua capacidade de polimerizar monômeros acrílicos ${ }^{49,50}$ e copolimerizar estireno com metacrilato de metila ${ }^{51}$ sem perda de atividade catalítica. O copolímero de estireno com metacrilato de metila é de baixo peso molecular ${ }^{51}$ e o teor de metacrilato de metila incorporado no copolímero permanece constante até $50 \%$ desse monômero na alimentação, com significativo aumento após essa concentração (Figura 9). Além disso, a conversão aumenta com o teor de monômero acrílico na alimentação. Esse comportamento pode ser atribuído à maior reatividade do metacrilato de metila, ou também à complexação do monômero acrílico com o alquilalumínio, que resultaria no decréscimo da densidade eletrônica da carbonila e, conseqüentemente, em sua capacidadade de complexação irreversível com o sítio catiônico ${ }^{52,53}$.

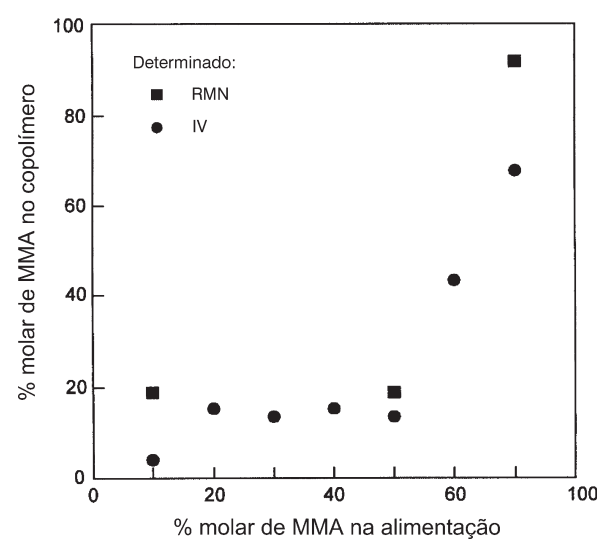

Figura 9. Teor de metacrilato de metila (MMA) no copolímero versus concentração de MMA na alimentação

Os espectros de RMN de ${ }^{13} \mathrm{C}$ dos copolímeros de metacrilato de metila e estireno obtidos foram comparados com os espectros publicados por $\mathrm{Gan}^{54}$, Aerdhts ${ }^{55}$ e Maxwel ${ }^{56}$ para o mesmo copolímero, com a distribuição de comonômeros de forma aleatória ou alternada. Como os espectros não coincidiam com nenhum destes, os autores concluíram que o copolímero deveria ser em bloco ${ }^{51}$.

\section{CONCLUSÃO}

Os catalisadores de níquel, principalmente aqueles contendo acetilacetonatos como ligantes, mostram-se ativos na polimerização de estireno. Esses catalisadores também são importantes na copolimerização de estireno com olefinas, dienos e monômeros polares. A estratégia de heterogeneizar esses catalisadores possibilita a obtenção de sistemas catalíticos com maior performance, principalmente no que diz respeito à atividade catalítica e estereoespecificidade. Além disso, torna possível a ativação apenas com o emprego de alquilalumínio como cocatalalisador. Dessa maneira, o desenvolvimento desses catalisadores pode levar ao desenvolvimento de novos materiais, por meio da copolimerização de estireno com monômeros polares, dienos e olefinas empregando-se sistema heterogêneo.

A versatilidade desses catalisadores torna possível uma melhor investigação do mecanismo de polimerização, elucidando as etapas de iniciação, propagação e transferência de cadeia.

\section{AGRADECIMENTOS}

Os autores agradecem ao CNPq (Bolsa de Produtividade em Pesquisa e PIBIC), ao Programa de Apoio às Entidades Estaduais (recursos financeiros repassados via FAPERJ APQ1 E-26/171.834 e APQ1 E-26/171.835), ao Fundo de Apoio à Pesquisa no Âmbito do Programa PROCIÊNCIA (FAP 2000) e à FAPERJ (Bolsa Cientista do Nosso Estado) pelo apoio financeiro na linha de pesquisa de polimerização por coordenação.

\section{REFERÊNCIAS}

1. Huang, J.; Rempel, G. L.; Prog. Polym. Sci. 1995, 20, 459.

2. Sinn, H.; Kaminsky, W.; Adv. Organomet. Chem. 1980, 18, 99.

3. Locatelli, P.; Trends Polym. Sci. 1994, $2,87$.

4. Gupta, V. K.; Satish, S.; Bhardwaj, I. I.; J. M. S. - Rev. Macromol. Chem. Phys. 1994, C34, 439.

5. Reddy, S. S.; Sivaram, S.; Prog. Polym. Sci. 1995, $20,309$.

6. Alt, H. G.; Russ. Chem. Bull. 1995, 44, 1.

7. Mülhaupt, R., Sernetz, F. G.; Suhm, J.; Heinemann, J.; Kautsch. Gummi Kunstst. 1998, 51, 286.

8. Kaminsky, W.; Catal. Today 2000, 62, 23.

9. Schellengerg, J.; Tomotsu, N.; Prog. Polym. Sci. 2002, 27, 1925.

10. Pó, R.; Cardi, N.; Prog. Polym. Sci. 1996, 21, 47

11. Hahn, L. C. ; Coronado, J.; Plástico Moderno 1994, julho, 8.

12. Campbell, R. E.; Newman, T. H.; Malanga, M. T.; Macromol. Symp. 1995, 97, 151.

13. Brintzinger, H. H.; Fischer, D.; Mulhaupt, R.; Rieger, B.; Waymouth, R. M.; Angew. Chem., Int. Ed. 1995, 34, 143.

14. Hamielec, A. E.; Soares, J. B. P.; Prog. Polym. Sci. 1996, 21, 651.

15. Hlatky, G. G.; Chem. Rev. 2000, 100, 1347.

16. Ittel, S. D.; Johnson, L. K.; Brookhart, M.; Chem. Rev. 2000, 100, 1169.

17. Mecking, S.; Coord. Chem. Rev. 2000, 203, 325.

18. Gates, D. P.; Svejda, S. A.; Oñate, E.; Killian, C. M.; Johnson, L. K.; White, P. S.; Brookhart, M.; Macromolecules 2001, 33, 2320.

19. Pó, R.; Cardi, N.; Santi, R.; Romano, Zannoni, C.; Spera, S.; J. Polym. Sci., Part A: Polym. Chem. 1998, 36, 2119.

20. Carlini, C.; Galletti, A. M. R.; Sbrana, G.; Caretti, D.; Polymer 2001, 42, 5069.

21. Ascenso, J.; Dias, A. R. ; Gomes, P. T ; Romão, C. C.; Neibecker, D.; Tkatchenko, I.; Reviilon, A.; Makromol. Chem. 1989, 190, 2773.

22. Ascenso, J.; Dias, A. R.; Gomes, P. T.; Romão, C. C.; Neibecker, D.; Tkatchenko, I.; Pham, Q. T.; Macromolecules 1989, 22, 998.

23. Crossetti, G. L.; Bormioli, C.; Ripa, A.; Giarusso, A; Porri, L.; Macromol. Rapid Commun. 1997, 18, 801.

24. Dias. M. L.; Crossetti, G. L.; Bormioli. C.; Giarusso, A.; Santa Maria, L. C. de; Coutinho, F. M. B.; Porri, L.; Polym. Bull. 1999, 40, 689.

25. Ferreira Jr., L. C.; Santa Maria, L. C. de; Costa, M. A. S.; Guimarães, P. I. C.; Polymer 2002, 43, 3857.

26. Ferreira Jr., L. C.; Santa Maria, L. C. de; Costa, M. A. S.; Guimarães, P. I. C.; Polym. Bull. 2002, 48, 463.

27. Zhao, C.; Ribeiro, M. R.; Portela, M. F.; Pereira, S.; Nunes, T.; Eur. Polym. J. 2001, 37, 45 .

28. Yasunaga, H.; Ichikawa, T.; Yamato, H.; Ikeda, M.; Yamato, H.; US pat. 3,464,965 1969

29. Endo, K.; Masaki, K.; Uchida, Y.; Polym. J. 1997, 29, 583.

30. Endo, K.; Masaki, K.; Macromol. Rapid Commun. 1995, 16, 779.

31. Endo, K.; Matsuda, Y.; J. Polym. Sci., Part A: Polym. Chem. 1999, $37,3838$.

32. Endo, K.; Matsuda, Y.; J. Polym. Sci., Part A: Polym. Chem. 2000, 38, 1241.

33. Coutinho, F. M. B ; Monteiro, L. F.; Costa, M. A. S.; Santa Maria, L. C. de; Menezes, S. M. C.; Polym. Bull. 1998, 40, 423.

34. Deng, H.; Shiono, T.; Soga, K.; Macromol. Chem. Phys. 1995, 196, 1971.

35. Marques, M. M.; Correia, S. G.; Ascenso, J. R.; Ribeiro, A. F. G.; Gomes, P. T.; Dias, A. R.; Foster, P.; Rausch, M. D.; Chien, J. C. W.; J. Polym. Sci., Part A: Polym. Chem. 1999, 37, 2457.

36. Chung, T. C.; Macromolecules 1988, 21, 865.

37. Babich, I. V.; Plyuto, Y. V.; Langeveld, A. D. V.; Moulljn, J. A.; Appl. Surf. Sci. 1997, 115, 267.

38. Tritto, I.; Sachi, M. M.; Locatelli, P.; Li, S. X.; Macromol. Chem. Phys. 1996, 197, 1537.

39. Babunsky, D. E.; Semikolenova, N. V.; Panchenko, V. N.; Sobólev, A. P.; Zakharov, V. A.; Talsi, E. P.; Macromol. Chem. Phys. 1997, 198, 3845.

40. Zakharov, I. I.; Zakharov, V. A.; Potapov, A. G.; Zhidomirov, G. M.; Macromol. Theory Simul. 1999, 8, 272. 
41. Mason, M. R.; Smith, J. M.; Bott, S. G.; Barron, A. R.; J. Am. Chem. Soc 1993, 115, 4971.

42. Petoff, J. L. M.; Myers C. L. M.; Waymouth, R. M.; Macromolecules 1999. 32,7984

43. Pó, R.; Cardi, N.; Abis, L.; Polymer 1998, 39, 959.

44. Kim, I.; Choi, C. S.; J. Polym. Sci., Part A: Polym. Chem. 1999, 32, 1523.

45. Nesmeyanov, A. N.; Isaeva, L. S.; Morozova, L. N.; Petrovskii, P. V.; Tumanskii, B. L.; Lokshin, B. V.; Klemenkova, Z. S.; Inorg. Chim. Acta 1980, $43,1$.

46. Duteil, A.; Schimid, G.; Zaika, W. M.; J. Chem. Soc. Chem. Commun. 1995 , 31.

47. Bovey, F. A.; High Resolution NMR of Macromolecules, Academic Press: New York, 1972, p. 147.
48. Kobayashi, E.; Hayashi, N.; Aoshima, S.; Furukawa, J.; J. Polym. Sci., Part A: Polym. Chem. 1998, 36, 241.

49. Endo, K.; Inukai, A.; Otsuo, T.; Macromol. Rapid. Commun. 1994, 15, 893.

50. Endo, K.; Macromol. Chem. Phys. 1999, 200, 1722.

51. Coutinho, F. M. B.; Costa, M. A. S.; Monteiro, L. F.; Santa Maria, L. C. de; Polym. Bull. 1997, 38, 303.

52. Yabuuchi, H.; Hirooka, M.; Kaetsu, I.; Polym. J. 1995, 27, 1054.

53. Yabuuchi, H.; Hirooka, M.; Kaetsu, I.; Polym. J. 1995, 27, 1021.

54. Gan, L. M.; Lee, X. C.; Chew, C. H.; Ng, S. C.; Gan, L. H.; Macromolecules 1994, 27, 6335.

55. Aerdts, A. M.; Haan, J. W. De; German, A.; Macromolecules 1993, 26, 1965.

56. Maxwell, I. A.; Aerdts, A. M.; German, A. L.; Macromolecules 1993, 26 , 1956. 